\title{
UTILIZATION OF CALCIUM SULFIDE DERIVED FROM WASTE GYPSUM BOARD FOR METAL-CONTAINING WASTEWATER TREATMENT
}

\author{
N. MIHARA ${ }^{1, *}$ \\ K. SOYA ${ }^{1}$ \\ D. KUCHAR ${ }^{1}$ \\ T. FUKUTA ${ }^{2}$ \\ H. MATSUDA ${ }^{1}$
}

Received: 06/11/07

Accepted: 14/12/07

\author{
${ }^{1}$ Deprt. of Energy Engineering and Science, Nagoya University \\ Furo-cho, Chikusa-ku, Nagoya 464-8603, Japan \\ ${ }^{2}$ Sanshin manufacturing Co., Ltd \\ 1-2 Kifuneura Haguro, Inuyama, 484-0894 Japan
}

\begin{abstract}
To achieve recycling of waste gypsum boards $\left(\mathrm{CaSO}_{4}\right)$, production of calcium sulfide by reductive decomposition of $\mathrm{CaSO}_{4}$ was investigated and the decomposition product of $\mathrm{CaS}$ was used as a sulfuration agent in the treatment of nickel-containing simulated wastewater. At the end of the experiment, residual nickel concentration and filtration characteristics of the slurry formed by adding $\mathrm{CaS}$ to the nickel-containing wastewater were investigated.

Regarding the reductive decomposition of $\mathrm{CaSO}_{4}$, it was found that $\mathrm{CaS}$ could be effectively generated by $\mathrm{CaSO}_{4}$ reductive decomposition with graphite and the CaS content in the final product was greater than $80 \%$ when the reductive decomposition was carried out for one hour at a temperature of $1273 \mathrm{~K}$, under $\mathrm{N}_{2}$ atmosphere.

Then, in the sulfuration treatment of nickel-containing wastewater with CaS, the applicability of $\mathrm{CaS}$ as a sulfuration agent was confirmed and the nickel concentration in the simulated wastewater was reduced from $100 \mathrm{mg}_{-\mathrm{Ni}} \mathrm{l}^{-1}$ to a value below $1.0 \mathrm{mg} \mathrm{I}^{-1}$, when the CaS was added to the simulated wastewater at $\mathrm{CaS}$ to $\mathrm{Ni}$ molar ratio of 1.3. Moreover, sulfide slurry obtained by adding CaS was characterized by lower average specific filtration resistance and compressibility coefficient, compared to hydroxide slurry formed by the conventional precipitation treatment.
\end{abstract}

KEYWORDS: Calcium Sulfide, Waste Gypsum, Reductive Decomposition, Waste Water Treatment, Sulfuration, Electroplating Solution

\section{INTRODUCTION}

In Japan, disposal of waste gypsum boards $\left(\mathrm{CaSO}_{4}\right)$ discharged from building demolitions has become a serious problem, due to a large amount of waste gypsum boards $\left(1.38 \times 10^{6}\right.$ tons, 2005 year) discarded as well as due to the shortage of landfill sites. Recently, an increase in the recycling of waste gypsum boards, as a material for a production of new gypsum boards, has been observed; however, the amount of gypsum boards recycled still remains relatively low. Therefore, to achieve a sustainable and environment-friendly society, it is necessary to develop a new waste gypsum recycling process. Generally, two approaches are considered for the reutilization of waste gypsum boards: material recycling and chemical recycling. Regarding the material recycling, waste gypsum boards are at first subjected to a crushing and board paper separation processes and then recycled as plasterboard material, cement material or soil improvement agent. In the case of chemical recycling, reductive decomposition of $\mathrm{CaSO}_{4}$ with a reducing agent has been studied. So far, the investigation on reductive decomposition of $\mathrm{CaSO}_{4}$ with $\mathrm{H}_{2}, \mathrm{C}$ and $\mathrm{CO}$ has been mainly undertaken to generate $\mathrm{SO}_{2}$ for the production of sulfuric acid as well as to recycle lime (CaO) from waste gypsum (Hull et al., 1957). In addition, the decomposition products of $\mathrm{SO}_{2}$ and $\mathrm{CaO}$, calcium sulfide (CaS), which can be used in the process of metal removal from metal-containing wastewater, were also reported to be generated by the reductive decomposition of $\mathrm{CaSO}_{4}$ via Eq. (1) and Eq. (2), (Wheelock et 
al., 1960; 1986).

$\mathrm{CaSO}_{4}+\mathrm{CO}=\mathrm{CaO}+\mathrm{SO}_{2}+\mathrm{CO}_{2}$

$\mathrm{CaSO}_{4}+4 \mathrm{CO}=\mathrm{CaS}+4 \mathrm{CO}_{2}$

Therefore, the CaS generation from $\mathrm{CaSO}_{4}$ and its subsequent utilization as a sulfuration agent in the treatment of metal-containing wastewater was investigated.

As a typical example of metal-containing wastewater, the rinsing wastewater discharged from electroplating industry has been chosen. Presently, the rinsing wastewater is treated with $\mathrm{NaOH}$ or $\mathrm{Ca}(\mathrm{OH})_{2}$, and the resulting metal hydroxide sludge is separated from the wastewater by a filtration process. However, the filterability of metal hydroxide sludge is quite poor, which results in generation of a large volume of sludge due to a high content of water. The metal hydroxide sludge is then usually disposed to landfills without any attempt to recover heavy metals involved in the sludge. Hence, to increase the separation efficiency and thus to decrease the sludge volume, a metal precipitation in the form of metal sulfides has been proposed. The metal sulfides are known to be superior to metal hydroxides in terms of their filtration characteristics as well as the total metal sludge volume (Fukuta et al., 2003).

Given the above, the utilization of gypsum boards for production of CaS, which could be subsequently applied in the sulfuration treatment of metal-containing wastewater, was proposed in our work. More specifically, the reductive decomposition behavior of $\mathrm{CaSO}_{4}$ was investigated to achieve a selective generation of $\mathrm{CaS}$ from waste gypsum boards. Then, the $\mathrm{CaS}$ generated from $\mathrm{CaSO}_{4}$ was used as a sulfuration agent in the treatment of a simulated nickel-containing wastewater and the mechanism of nickel sulfide precipitation was investigated. In addition, the average specific filtration resistance of the slurry formed by adding $\mathrm{CaS}$ generated from $\mathrm{CaSO}_{4}$ to the nickel-containing wastewater was determined.

\section{EXPERIMENTAL}

\subsection{CaS generation from $\mathrm{CaSO}_{4}$}

The sample used in this study was prepared by grinding and screening $\mathrm{CaSO}_{4} \cdot 2 \mathrm{H}_{2} \mathrm{O}$ of commercial reagent grade (Wako Chemicals, Japan) to a mean particle diameter in the range of $63-100 \mu \mathrm{m}$. As a reducing agent, graphite of commercial reagent grade $(63-100 \mu \mathrm{m})$ was added to the $\mathrm{CaSO}_{4} \cdot 2 \mathrm{H}_{2} \mathrm{O}$ to adjust the prescribed mixing ratio. The reductive decomposition of $\mathrm{CaSO}_{4}$ was carried out by using a gas-flow type tubular reactor, as shown in Figure 1.

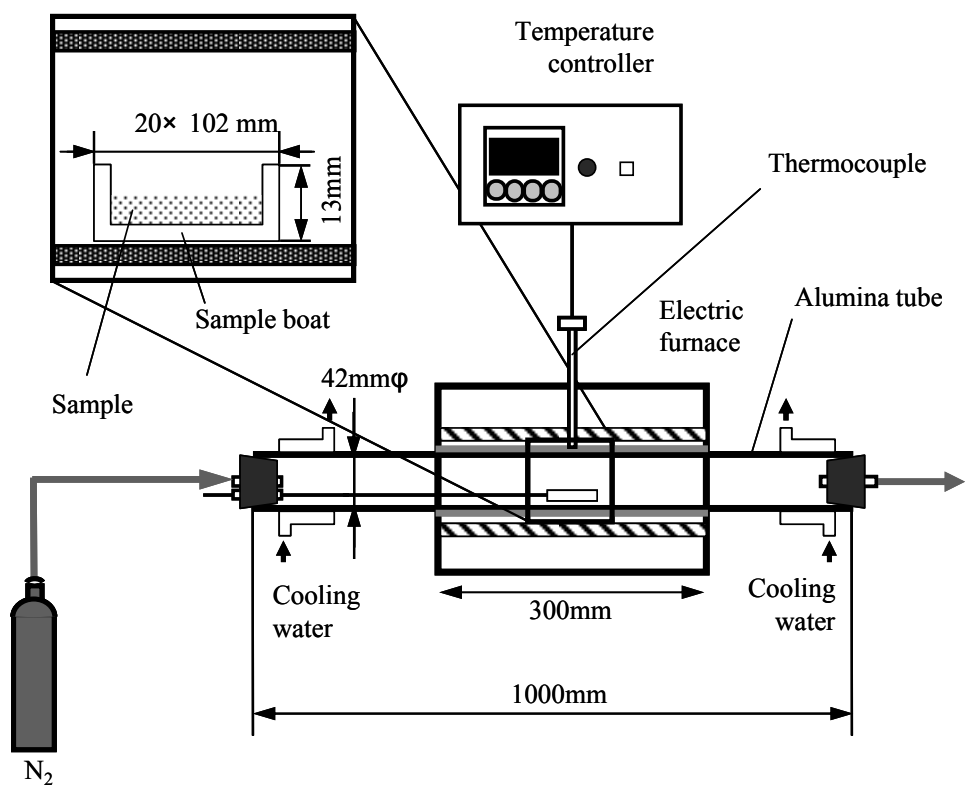

Figure 1. Experimental apparatus

The reactor temperature was controlled at a given reaction temperature (973-1273 K) using a temperature-controllable electric furnace. The sample reductive decomposition was conducted under $\mathrm{N}_{2}$ atmosphere $\left(\mathrm{N}_{2}: 30 \mathrm{ml} \mathrm{min}^{-1}\right)$ for a time period of one hour. 
After the experiments, the sample residue was collected and CaS content in the sample was determined using ISO 680:1990 analytical method (ISO, 1990). Then, $X_{C a s}$ parameter calculated by Eq. (3) was used to evaluate the purity of CaS product.

$\mathrm{X}_{\mathrm{CaS}}=\frac{\mathrm{M}_{\mathrm{CaS}}}{\mathrm{M}_{\mathrm{CaSO} 4}}$

$M_{\text {CaS }}$ is the molar amount of the CaS content in a sample residue determined after experiment and $\mathrm{M}_{\mathrm{CaSO}}$ is the initial molar amount of $\mathrm{CaSO}_{4}$ in the sample.

In addition, the sample residue was subjected to X-ray Powder Diffraction Analysis (XRD, RINT-2500 TTR, Rigaku Model) and the crystalline compounds formed during $\mathrm{CaSO}_{4}$ decomposition were identified.

\subsection{Sulfuration treatment of nickel-containing wastewater with CaS}

Figure 2 shows the flow chart of experimental procedure. Nickel sulfate hexahydrate ( $\mathrm{NiSO}_{4} \cdot 6 \mathrm{H}_{2} \mathrm{O}$, Wako Chemicals, Japan) aqueous solution of $100 \mathrm{mg}_{-\mathrm{Ni}} \mathrm{I}^{-1}$ was employed as simulated wastewater. At first, a given amount of sulfuration agent obtained by the procedure described in section 2.1 (CaS purity $=80 \%$ ) was added into the sample solution. The slurry was stirred for 10 minutes and then allowed to settle for another 10 minutes. Subsequently, the slurry was filtered using a paper filter with a mean pore size of $0.45 \mu \mathrm{m}$. The nickel concentration in the filtrate was measured using an ICP (ICP, Vista-MPX Simultaneous ICP-OES, Varian, Inc.). The filter cake/precipitate was dried at a temperature of $378 \mathrm{~K}$ for 2 hours, and the crystallographic composition was analyzed using an XRD Analysis.

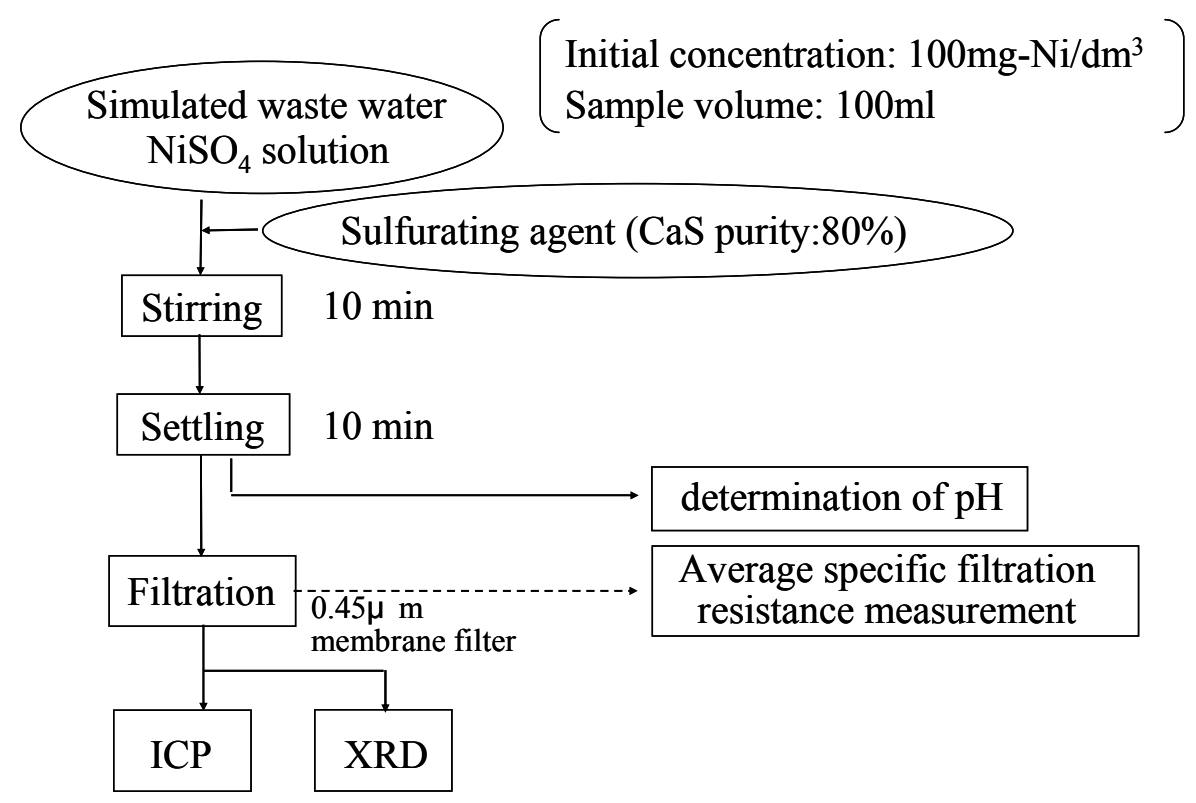

Figure 2. Flow chart of the experimental procedure

\subsection{Evaluation of filtration characteristics}

Figure 3 shows the experimental filtration testing apparatus used to determine the average specific filtration resistance of the slurry obtained by sulfuration treatment of $2000 \mathrm{mg}_{-\mathrm{Ni}} \mathrm{l}^{-1}$ $\mathrm{NiSO}_{4} \cdot 6 \mathrm{H}_{2} \mathrm{O}$ aqueous solution with CaS. In these experiments, a paper filter with filtration area of $1.02 \times 10^{-3} \mathrm{~m}^{2}$ and a mean pore size of $0.45 \mu \mathrm{m}$ was used. 


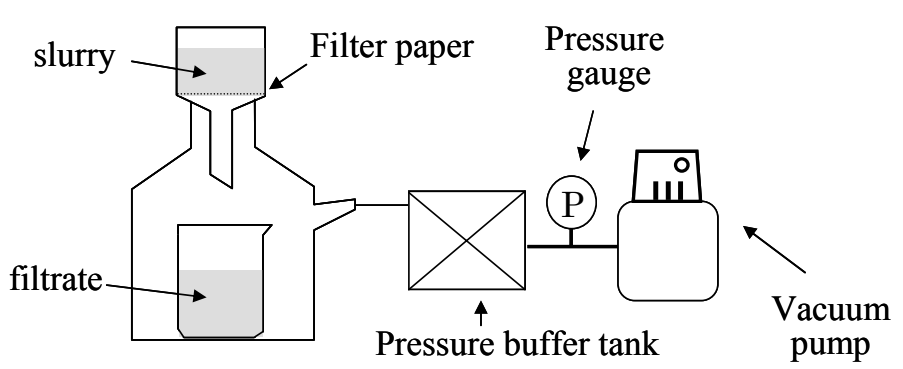

Figure 3. Schematic diagram of filtration testing apparatus

The relation between filtrate volume $(V)$ and filtration time $(\theta)$ is given by Ruth's equation shown in Eq. (4) (Ruth et al., 1933, 1935, 1946).

$\frac{\mathrm{d} \theta}{\mathrm{dV}}=\frac{\mu \rho s \alpha}{\mathrm{A}^{2}(1-\mathrm{ms}) \mathrm{p}}\left(\mathrm{V}+\mathrm{V}_{\mathrm{m}}\right)$

where $\mu$ is the filtrate viscosity, $\rho$ is the filtrate density, $s$ is the concentration of the slurry, $A$ is the filtration area, $p$ is the filtration pressure and $V_{m}$ is the theoretical filtrate volume required to form a filter cake of resistance equal to medium resistance. In the determination of average specific filtration resistance $(\alpha), d \theta / d V$ was plotted against $V$ and the value of coefficient on the right side of Eq. (2) was determined from the slope of this plot. Consequently, the average specific filtration resistance $(\alpha)$ was determined.

Further, in order to determine the compressibility coefficients $(n)$, filtration resistance under different filtration pressure was measured, and then the compressibility coefficients were calculated using Eq. (5)

$\alpha=\alpha_{0}+\alpha_{1} p^{n}$

where $\alpha_{0}$ and $\alpha_{1}$ are constants (Ruth et al., 1933; 1935; 1946).

For a comparison, the average specific filtration resistance and the compressibility coefficients of the slurry generated with sodium hydroxide $(\mathrm{NaOH})$ as commonly used the rinsing wastewater treatment were also measured.

\section{RESULTS AND DISCUSSION}

\subsection{Generation of CaS by reductive decomposition of $\mathrm{CaSO}_{4}$}

The reductive decomposition of $\mathrm{CaSO}_{4} \cdot 2 \mathrm{H}_{2} \mathrm{O}$ with graphite $\left(\mathrm{C} / \mathrm{CaSO}_{4}\right.$ molar ratio $\left.=4.0\right)$ was conducted under $\mathrm{N}_{2}$ atmosphere for one hour. Figure 4 shows the effect of reaction temperature on the $\mathrm{CaSO}_{4}$ reductive decomposition with graphite expressed in terms of $X_{\text {Cas. }}$.

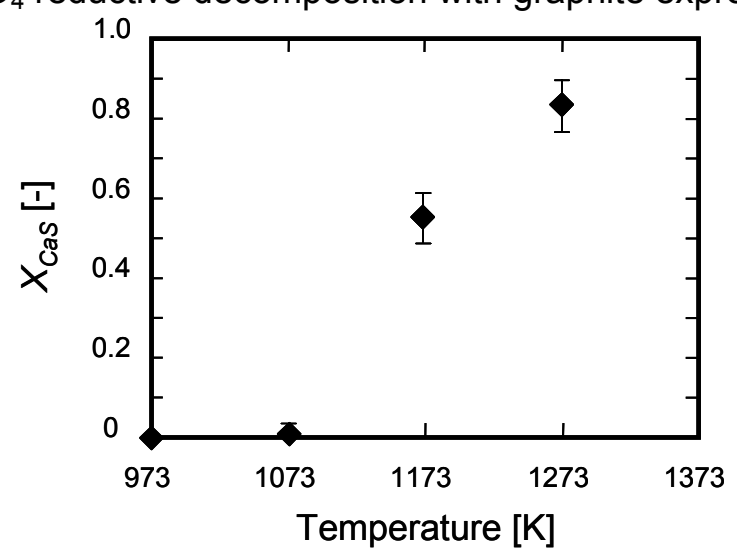

Figure 4. Effect of reaction temperature on the $\mathrm{CaSO}_{4}$ reductive decomposition

$\left(\mathrm{C} / \mathrm{CaSO}_{4}\right.$ molar ratio $\left.=4.0\right)$

It was found that the reductive decomposition of $\mathrm{CaSO}_{4}$ to $\mathrm{CaS}$ in the presence of graphite first occurred at temperatures above $1073 \mathrm{~K}$ and the $X_{\text {Cas }}$ greater than 0.8 was obtained at a temperature of $1273 \mathrm{~K}$. When the $\mathrm{CaSO}_{4}$ decomposition residues obtained at temperatures below $1173 \mathrm{~K}$ were analyzed using $\mathrm{XRD}$, unreacted $\mathrm{CaSO}_{4}$ was still found in these residues. 
By contrast, at a temperature of $1273 \mathrm{~K}$, only decomposition products of $\mathrm{CaS}$ and $\mathrm{CaO}$ as well as non-reacted graphite were detected confirming complete decomposition of $\mathrm{CaSO}_{4}$ at a temperature of $1273 \mathrm{~K}$. Figure 5 shows the XRD patterns of sample residue obtained at $1273 \mathrm{~K}$.

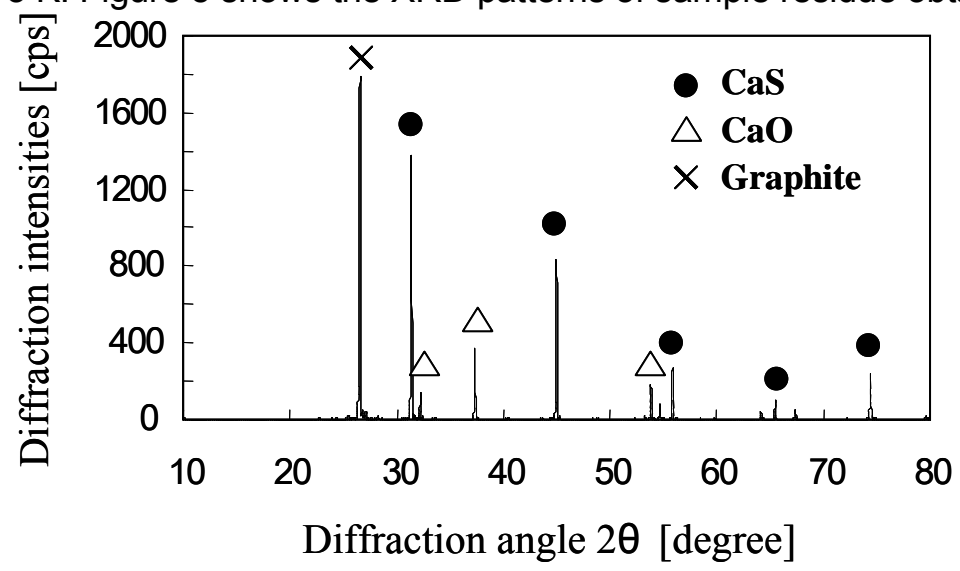

Figure 5. X-ray diffraction patterns of sample residue $\left(\mathrm{C} / \mathrm{CaSO}_{4}\right.$ molar ratio $=4.0$, Temperature $\left.=1273 \mathrm{~K}\right)$

To increase the CaS yield, the effect of graphite addition on $\mathrm{CaSO}_{4}$ reductive decomposition was investigated. Figure 6 shows the values of $X_{\text {Cas }}$ obtained at $1273 \mathrm{~K}$ for different graphite additions. It can be seen that the $X_{\text {Cas }}$ greater than 0.8 was obtained when $\mathrm{C} / \mathrm{CaSO}_{4}$ molar ratio was increased to 3.0. However, no additional increase in $X_{C a s}$ value was obtained when the $\mathrm{C} / \mathrm{CaSO}_{4}$ molar ratio was further increased beyond 3.0. In addition, a large amount of unreacted graphite was detected in the sample residues obtained at $\mathrm{C} / \mathrm{CaSO}_{4}$ equal or higher than 4.0. Thus, the optimum $\mathrm{C} / \mathrm{CaSO}_{4}$ molar ratio was determined to be 3.0.

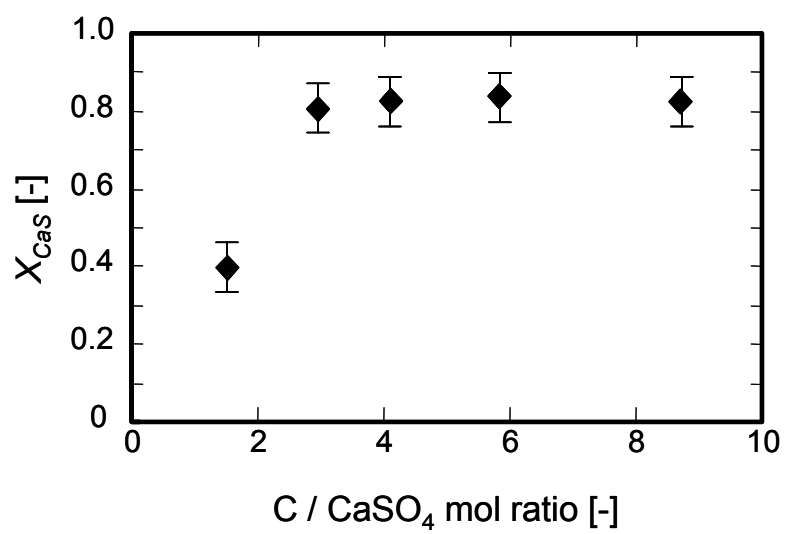

Figure 6. Effect of graphite addition on $\mathrm{CaSO}_{4}$ reductive decomposition $($ Temperature $=1273 \mathrm{~K})$

\subsection{Sulfuration treatment of nickel-containing wastewater with CaS}

Sulfuration treatment of nickel-containing wastewater with sulfuration agent $\left(X_{C a S}=0.8\right)$ obtained in section 3.1 was conducted. The $\mathrm{CaS} / \mathrm{Ni}$ molar ratio was varied from 0.5 to 2.7 and the nickel concentrations determined in the respective filtrate are shown in Figure 7 . It can be seen that the nickel concentration was reduced from the original value of $100 \mathrm{mg}_{-\mathrm{Ni}}{ }^{-1}$ to a value below $1.0 \mathrm{mg} \mathrm{l}^{-1}$ when the molar ratio of CaS to $\mathrm{Ni}$ was adjusted to 1.3 . Such a result confirmed that $\mathrm{CaS}$ formed by reductive decomposition of $\mathrm{CaSO}_{4}$ can be used to remove nickel ions from wastewater.

Regarding the reaction mechanism, the Eqs. (6)-(10) were considered to take place (Kim, 1980):

$\mathrm{CaS}=\mathrm{Ca}^{2+}+\mathrm{S}^{2-}$

$\mathrm{Me}^{2+}+\mathrm{S}^{2-}=\mathrm{MeS}$ 
$2 \mathrm{CaS}+2 \mathrm{H}_{2} \mathrm{O}=\mathrm{Ca}(\mathrm{HS})_{2}+\mathrm{Ca}(\mathrm{OH})_{2}$

$\mathrm{Ca}(\mathrm{HS})_{2}=\mathrm{Ca}^{2+}+2 \mathrm{HS}^{-}$

$\mathrm{Me}^{2+}+\mathrm{HS}^{-}=\mathrm{MeS}+\mathrm{H}^{+}$

In addition, $\mathrm{pH}$ value of the filtrate was observed to increase as the CaS/Ni molar ratio was increased owing to the generation of $\mathrm{Ca}(\mathrm{OH})_{2}$ from CaS according to Eq. (8) or from $\mathrm{CaO}$ originally involved in the sulfuration agent.

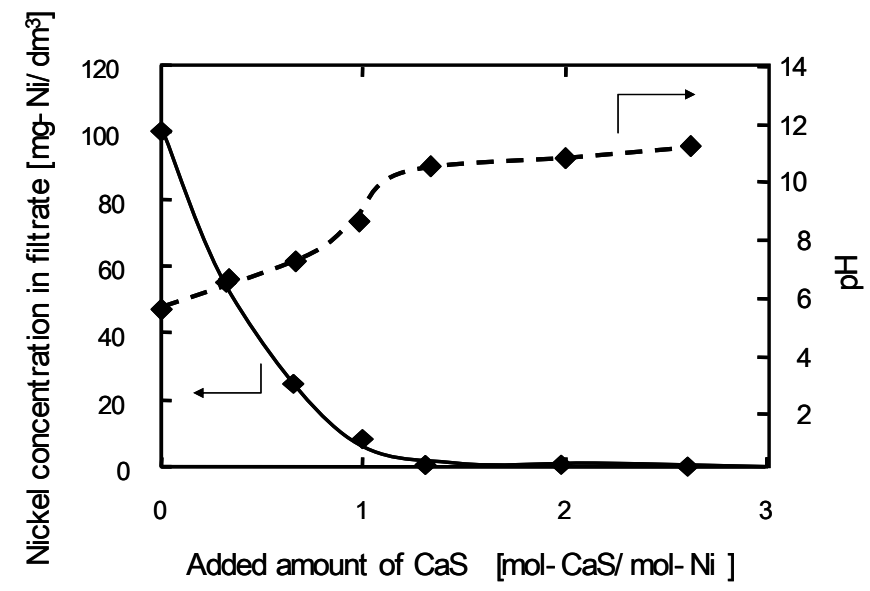

Figure 7. Effect of CaS addition on nickel concentration in filtrate

\subsection{Filtration characteristics of sulfide slurry obtained by adding CaS}

Figure 8 shows the average specific filtration resistances of the slurries plotted against filtration pressure. For a comparison, the slurry obtained by nickel ions precipitation with sodium hydroxide was also subjected to filtration test. As a result, it was confirmed that the average specific filtration resistance of metal sulfide slurries was smaller than that of hydroxide slurry.

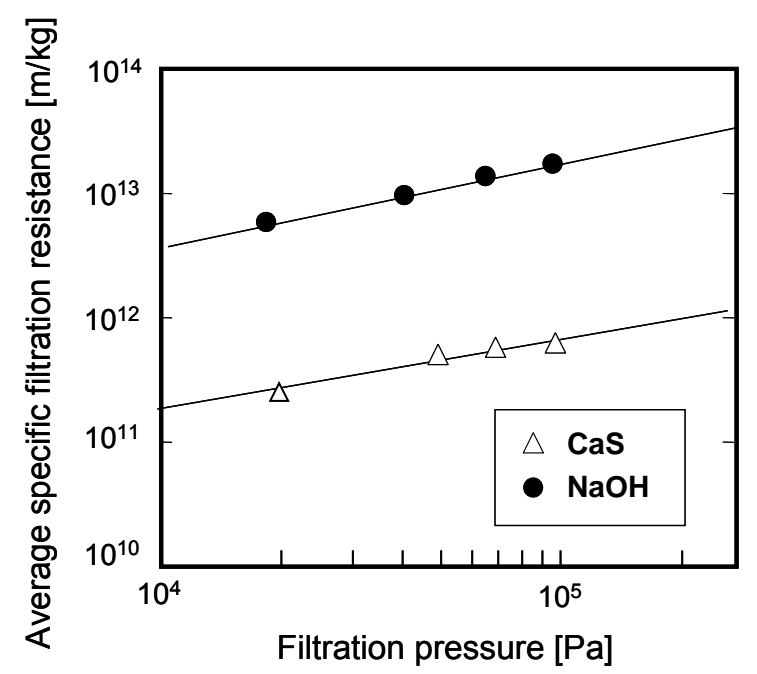

Figure 8. Average specific filtration resistances at each filtration pressure measured by experimental filtration tests

In Figure 8, the average specific filtration resistance and filtration pressure were plotted in logarithmic scale and the compressibility coefficients were determined from the slopes of each line, based on the logarithmic form of Eq. (5).

Table 1 summarizes the compressibility coefficients and it can be seen that compressibility coefficient of filter cake obtained with CaS as a precipitation agent was significantly lower than that of $\mathrm{NaOH}$. 
Table 1. Compressibility of filter cake

\begin{tabular}{ccc}
\hline Precipitant & CaS & $\mathrm{NaOH}$ \\
\hline Compressibility coefficients [-] & 0.59 & 0.66 \\
\hline
\end{tabular}

\section{CONCLUSIONS}

Reductive decomposition of $\mathrm{CaSO}_{4}$ was investigated in this work and the decomposition product of CaS was used as a sulfuration agent in the treatment of nickel-containing simulated wastewater.

As for the reductive decomposition of $\mathrm{CaSO}_{4}$, it was found that $\mathrm{CaS}$ can be effectively generated by $\mathrm{CaSO}_{4}$ reductive decomposition with graphite and the CaS content in the final product was greater than $80 \%$ when the reductive decomposition was carried out for one hour at a temperature of $1273 \mathrm{~K}$, under $\mathrm{N}_{2}$ atmosphere.

In the sulfuration treatment of nickel-containing wastewater with CaS, the applicability of CaS as a sulfuration agent was confirmed and the nickel concentration in the simulated wastewater was reduced from $\left.100 \mathrm{mg}_{-\mathrm{Ni}}\right|^{-1}$ to a value below $1.0 \mathrm{mg} \mathrm{l}^{-1}$, when the CaS was added to the simulated wastewater at $\mathrm{CaS}$ to Ni molar ratio of 1.3.

Moreover, sulfide slurry obtained by adding CaS was characterized by lower average specific filtration resistance and compressibility coefficient compared to hydroxide slurry formed by the conventional precipitation treatment.

\section{REFERENCES}

Fukuta T., Ito T., Sawada K., Ozawa S., Kojima Y., Matsuda H. and Yagishita K., (2003), Improvement of Nickel-Precipitation from Aqueous Nickel Solution by Sulfuration with Sodium Sulfides, J. Chem. Eng., Japan, 36(4), 493-498.

Hull W.Q., Schon F. and Zirngibl H., (1957), Sulfuric Acid from Anhydrite, Ind. Eng. Chem., 49(8), 1204-1214.

ISO 680:1990, (1990), Cement - Test methods - Chemical analysis, International Standards Organization.

Kim B.M., (1980), Treatment of Metal Containing Wastewater with Calcium Sufide, AIChE symposium series WATER, 77(209), 39-48.

Ruth B.F., Montillon, G.H. and Montonna, R.E., (1933), Studies in Filtration, I Critical Analysis of Filtration Theory, Ind. Eng. Chem., 25, 76-82.

Ruth B.F., Montillon G.H. and Montonna R.E., (1933), Studies in Filtration, II Fundamental Axiom of Constant-Pressure Filtration, Ind. Eng. Chem., 25,153-161.

Ruth B.F., (1935), Studies in Filtration, III Derivation of General Filtration Equation, Ind. Eng. Chem., 27, 708-723.

Ruth B.F., (1935), Studies in Filtration, IV Nature of Fluid Flow through Filter Septa and Its Importance in the Filtration Equation, Ind. Eng. Chem., 27, 806-816.

Ruth B.F., (1946), Correlating Filtration Theory with Industrial Practice, Ind. Eng. Chem., 38, 564-571.

Wheelock T.D. and Boylan D.R., (1960), Reductive Decomposition of Gypsum by Carbon Monoxide, Ind. Eng. Chem., 52, 215-218.

Wheelock T.D. and Morris C.E., (1986), Recovery of Sulfur Dioxide and Lime from Waste Gypsum, TIZ-Fauchberichite., 1, 37-46. 